Professor e estilista. Leciona nos cursos de graduação e pós-graduação de diversas escolas de moda, em São Paulo, as disciplinas História da Arte, História da Moda, Cultura de Moda e Estética. É autor dos livros História da moda: uma narrativa e Reflexões sobre moda, v. I, II, III e IV, Um século de moda, e coautor de História da moda no Brasil:das influências às autorreferências.

\title{
Cinema e moda
}

$[38$

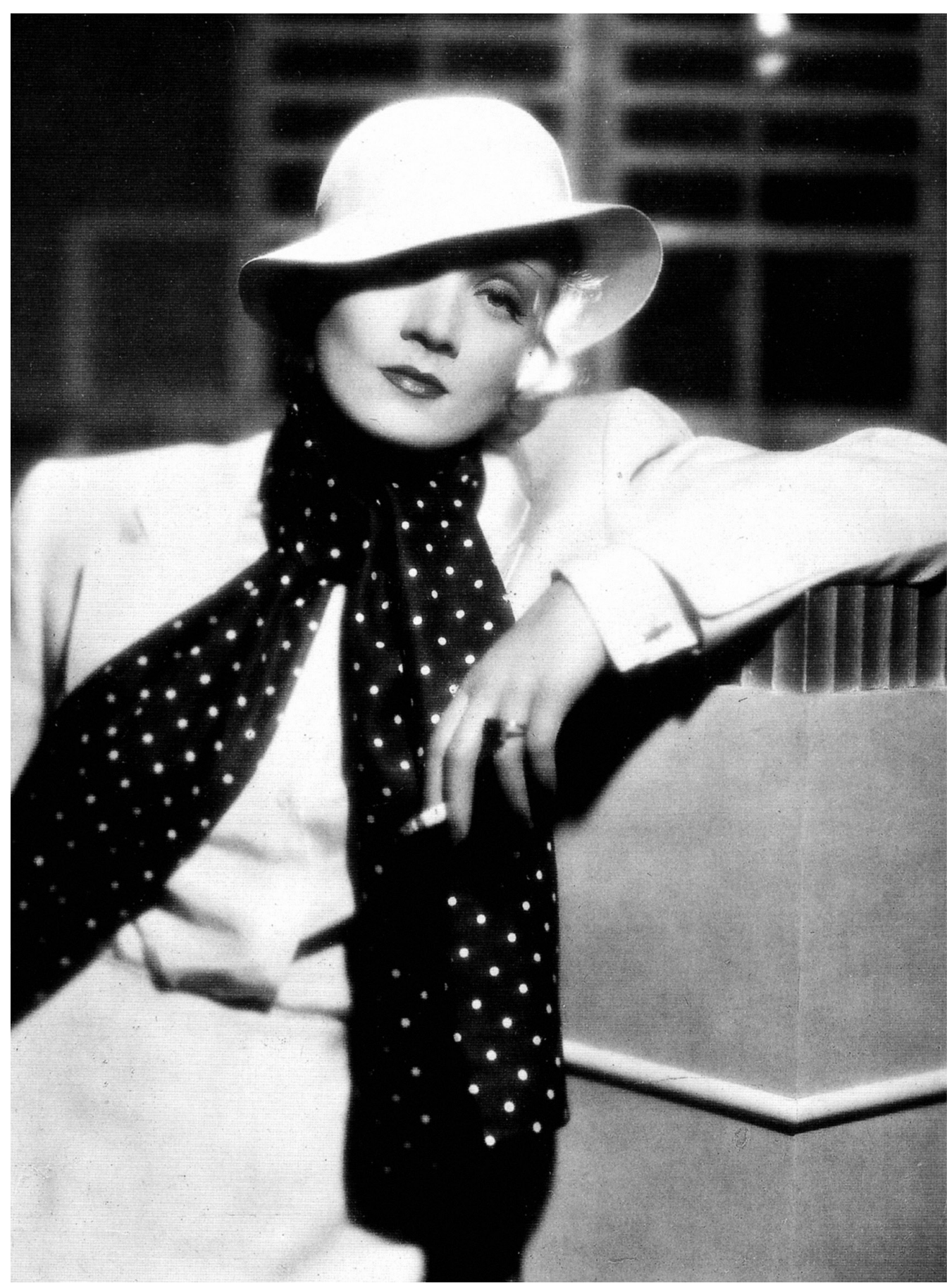


Algumas são as possibilidades de diálogo entre cinema e moda. Pode-se assim entender quando um filme é capaz de influenciar as massas por intermédio de sua exibição e, na sequência, o consequente uso coletivo de roupas, acessórios, calçados, penteados etc. baseados no seu respectivo figurino; pode-se também interpretar esse diálogo quando um profissional da moda (costureiro e/ou estilista) é convidado a criar o figurino para o filme; igualmente, é possivel analisar essa interface por meio da influência que um filme exerce no comportamento e modo de ser e, por extensão, no modo de se vestir; outra possibilidade é a capacidade que o cinema tem de reconstituir um período histórico, o que exige um estudo aprofundado de indumentária e/ou moda a fim de estabelecer uma identidade o mais real possível ao período referenciado. Sendo assim, estas e outras leituras nos conduzem a possibilidades de amálgama das áreas supracitadas.

Neste breve artigo sobre cinema e moda, escolho, livremente e de maneira concisa, sete possiveis relações de aproximação entre o cinema e a moda.

\section{Anos 1930}

Esta década do século $X X$, analisada pelo ângulo da moda, teve nítidas influências de usos coletivos nas roupas exercidas pelo cinema norte-americano. As divas, platinadas ou não, enlouqueciam as espectadoras das salas de projeção nas ditas "cinelândias" - os centros de cidades grandes nos quais havia grande concentração de cinemas -, a ponto de muitas delas irem assistir aos filmes munidas de prancheta, lápis e papel para tentar desenhar as roupas que atrizes como Marlene Dietrich, Greta Garbo, Veronica Lake, Joan Crawford, Jean Harlow, entre outras, usavam para poder levar as suas respectivas costureiras, na tentativa de fazer roupas as mais fiéis possíveis àquelas das atrizes.

Sem dúvida, houve grande investimento do governo norte-americano na área do cinema, possibilitando belas películas romantizadas, e até os musicais, para favorecer ao povo a capacidade de sonhar com momentos melhores devido à crise advinda com a queda da Bolsa de Valores de Nova York, em 1929. Estratégia que deu certo à época e tornou-se uma prática em diversos filmes possibilitando a ligação entre cinema e moda.

\section{Os figurinistas Gilbert Adrian e Edith Head}

Mestres em seus ofícios, ambos foram, indiretamente, nomes tão importantes na História da Moda, quanto alguns profissionais especificos do setor, especialmente comparando-os aos(às) costureiros(as) franceses(as).

Gilbert Adrian (1903-1959) nasceu nos Estados Unidos, estudou arte e tornou-se um dos figurinistas mais renomados do cinema norte-americano. Vestia inúmeras atrizes famosas e muito influenciou a moda, especialmente quando criou uma roupa branca para Joan Crawford na qual Ihe acentuava os ombros e estreitava a cintura. Em 1943, chegou a abrir loja própria, desligando-se do cinema, ainda que eventualmente fizesse alguns trabalhos livres.

Edith Head (1898-1981) também nasceu nos Estados Unidos e foi uma das figuras mais emblemáticas do cinema norte-americano na área de figurino. Vestiu grandes atrizes em filmes que ficaram muito famosos, influenciando decisivamente o mundo da moda. Trabalhou em mais de 400 filmes e, ao longo de mais de 40 anos como figurinista de cinema, teve 35 indicações ao Oscar e ganhou 8 estatuetas de melhor figurino.

\section{3. "Fashions of 1934"}

Este filme de 1934, dirigido por Willian Dieterle, é sensacional, um verdadeiro sonho, até mesmo surreal, mescla de humor e crítica ao setor da moda, principalmente pelo viés da cópia norte-americana da moda francesa. De fato, a criação francesa e a cópia pelo restante do mundo ocidental no universo da moda já era uma constante, a ponto de ser motivo inspirador para esse filme.

Pouco conhecida e divulgada no Brasil, essa película em preto e branco, estrelada por Bette Davis em princípio de carreira, é um entretenimento de primeira linha tanto para cinéfilos quanto para fashionistas. 


\section{Filmes de reconstituição histórica}

Trata-se de outra maneira de dialogar com a moda, só que resgatando aspectos pretéritos. Inúmeros são os filmes que o fazem com propriedade por intermédio de seus figurinos, inclusive reconstituindo épocas anteriores ao surgimento do conceito de moda, que se deu entre o final da Idade Média e o início da Idade Moderna.

Seja a época que for, o figurino, assim como a trilha sonora, locação, iluminação, direção de arte, o olhar e a intenção do diretor são fundamentais para o resgate histórico do periodo abordado. Tem-se a impressão de que quase todos os periodos históricos e/ou culturas já foram contemplados pelo cinema mundial, tornando-se um deleite apreciativo e até mesmo referência na ajuda da contextualização de época.

\section{Filmes contemporâneos que tratam da moda}

A moda, desde as últimas décadas do século XX, está na moda. Talvez por sua realidade efêmera ter entrado em diálogo acirrado com as superficialidades, imediatismos e transitoriedades contemporâneas. Assim, a própria moda inspira filmes que tratam do seu universo expressivo. Como exemplo, destaco Prêt-à-Porter (Robert Altman, 1994), que esclarece muito sobre criação/divulgação, consumo de moda, valores estéticos e conceituais, os profissionais envolvidos na área, como jornalistas, fotógrafos e modelos; Unzipped (Douglas Keeve, 1995), que retrata o processo criativo de Isaac Mizhari; Zuzu Angel (Sérgio Rezende, 2006), que documenta a vida e a obra dessa estilista mineira radicada no Rio de Janeiro e todo o seu processo criativo baseado na dor pela morte de seu filho, Stuart Angel; O Diabo Veste Prada (David Frankel, 2006), que aborda o jornalismo de moda e a vida contemporânea extremamente corrida dos profissionais do setor; Coco Avant Chanel (Anne Fontaine, 2009), que conta parte da vida de mademoiselle Chanel e como ela chegava às suas conclusões criativas sobre a moda feminina no principio do século XX.

\section{Oscar de filme, Oscar de figurino e figurino para o Oscar}

Anualmente, a Academia de Hollywood agracia com o Oscar, prêmio mais cobiçado na área do cinema internacional, um filme, como sendo o melhor, e diversas outras áreas especificas que envolvem a elaboração de uma fita. 0 figurino é uma delas, e, muitas vezes, mesmo sendo um filme de caráter histórico, este é capaz de influenciar o comportamento de moda, como foi o caso de Amadeus (Milos Forman, 1984), Oscar de melhor filme, que conta a vida de Mozart; Entre Dois Amores (Sidney Pollack, 1985), Oscar de melhor direção, retrata uma relação afetiva na África dos anos 1920, e inúmeros outros filmes que influenciaram a moda, além de ter figurinos de alto valor na contextualização da época. No meu pretenso crivo, uma das melhores películas de reconstituição histórica foi $A$ Época da Inocência (Martin Scorsese, 1993), estrelado por Michelle Pfiffer, Daniel Day-Lewis e Winona Hyder, num pungente triângulo amoroso que recebeu duas estatuetas nas categorias de melhor figurino e melhor direção de arte.

Atualmente, outro diálogo entre Oscar e moda está na entrega do prêmio como melhor divulgação para a alta-costura; os costureiros sempre querem vestir as atrizes indicadas a qualquer prêmio, ou até mesmo aquelas que só vão ao evento, certos de que o "tapete vermelho" tem sido uma excelente passarela para a área.

\section{7) Biennale de Firenze}

A cidade de Florença, juntamente às de Prato e Livorno, na Itália, hospedaram a primeira Bienal Internacional de Moda, em 1996, com o tema II Tempo et la Moda. Em 1998, o cinema foi escolhido como tema para Bienal: La Moda Veste il Cinema. Nessas cidades, vários locais, entre museus, espaços expositivos e outros, que acolheram as diversas leituras do cinema com a moda, tais como filmes que influenciaram a moda, estilistas, figurinistas, filmes históricos e uma série de outras possibilidades de possiveis diálogos.

Nesse sentido, é a própria moda ganhando cada vez mais o status de arte por seu viés criativo e sua capacidade de contextualizar o tempo, chegando inclusive ao espaço museográfico e servindo de assunto para uma Bienal especifica do setor $\mathrm{e}_{\text {, }}$ obviamente, também com a contribuição do cinema para sua divulgação. 